\title{
Effect of adhesive application methods on bond strength to bovine enamel
}

\author{
Susumu Ando ${ }^{1,2)}$, Takayuki Watanabe ${ }^{1)}$, Keishi Tsubota ${ }^{1,2)}$, Takeshi Yoshida ${ }^{1)}$, \\ Atsushi Irokawa ${ }^{1,2)}$, Toshiki Takamizawa ${ }^{1,2)}$, Hiroyasu Kurokawa ${ }^{1,2)}$ and \\ Masashi Miyazaki ${ }^{1,2)}$ \\ ${ }^{1)}$ Department of Operative Dentistry, Nihon University School of Dentistry, Tokyo, Japan \\ ${ }^{2)}$ Division of Biomaterials Science, Dental Research Center, Nihon University School of Dentistry, \\ Tokyo, Japan
}

(Received 17 March and accepted 8 April 2008)

\begin{abstract}
Single-step self-etch adhesive systems have been developed to simplify and shorten bonding procedures. With the gain in popularity of these simplified systems, their reliability has become a focus of interest. The purpose of this study was to determine the effect of adhesive application method on enamel bond strength. Two commercial single-step self-etch adhesive systems, Clearfil tri-S Bond, and G-Bond, were used. Bovine mandibular incisors were mounted in self-curing resin and the facial enamel surfaces were ground wet on 600-grit $\mathrm{SiC}$ paper. Adhesives were only applied without agitation (inactive) or were agitated by a brush (active), and resin composites were condensed into the mold on the enamel surface and light-activated. Ten specimens per test group were stored in water at $37^{\circ} \mathrm{C}$ for $24 \mathrm{~h}$, then shear-tested at a cross-head speed of $1.0 \mathrm{~mm} / \mathrm{min}$. Two-way ANOVA followed by the Tukey HSD test were used. The bond strengths for active application were higher than those for inactive application. Significant differences were found for both adhesive systems. From the results of this study, active application of single-step self-etch adhesive may help to ensure the creation of a roughened enamel surface and enhance the penetration of resin monomer into the subsurface demineralized enamel. (J. Oral Sci. 50, 181186, 2008)
\end{abstract}

Correspondence to Dr. Masashi Miyazaki, Department of Operative Dentistry, Nihon University School of Dentistry, 1-8-13 Kanda-Surugadai, Chiyoda-Ku, Tokyo 101-8310, Japan Tel: +81-3-3219-8141

Fax: +81-3-3219-8347

E-mail: miyazaki-m@dent.nihon-u.ac.jp
Keywords: single-step adhesive; enamel bond strength; application method.

\section{Introduction}

The demand for esthetic dental materials has generated the development of many adhesive systems to provide sufficient bonding ability to both enamel and dentin. To reduce technique sensitivity that affects the bonding ability of adhesive systems (1-3), the steps required for bonding procedures have been reduced. Single-step self-etch adhesive systems have been developed to simplify and shorten bonding procedures $(4,5)$. Theoretically, singlestep self-etch adhesive forms a continuous layer between the composite resin and the tooth surface simultaneously demineralized with acidic monomers and resin monomer penetration into the tooth substrate (6-8).

The depth of the enamel surface removed during the etching procedure depends on the type of acid, the acid concentration, the duration of etching and the chemical composition of the surface (9-12). A morphological study of the etched enamel surface has demonstrated that the application of single-step self-etch adhesive did not create a deep enamel etching pattern compared to those of phosphoric acid (13). Some concerns remain regarding both the short- and long-term bonding effectiveness of singlestep self-etch adhesive systems to enamel, in particular when so-called 'mild' self-etch adhesives are employed (14). Some manufacturers even recommend the adjunctive use of phosphoric acid when bonding to enamel, especially in the case of non-instrumented enamel. Since enamel bonding is primarily based on micromechanical interlocking 
of a low-viscosity resin into micro-porosities, the extent and depth of the etching pattern should logically influence the bonding performance of an adhesive (15). It has been repeatedly demonstrated that this etching pattern largely depends on the acidity of the conditioner, although there is no consensus regarding the use of mild single-step selfetch adhesives on enamel.

It can be hypothesized that single-step self-etch adhesives are capable of implementing sufficient etching with active application of enamel such that an adequate micromechanical bond with a bonding agent can be formed. The purpose of this study was to determine the effect of singlestep self-etch adhesive application methods on bond strength to bovine enamel.

\section{Materials and Methods}

Two commercial single-step self-etch adhesive systems, Clearfil tri-S Bond (CT, Kuraray Medical Co., Tokyo, Japan), and G-Bond (GB, GC Corp. , Tokyo, Japan) were used, as shown in Table 1. A visible-light-activating unit Optilux 501 (SDS Kerr, Danbury, CT, USA) was used, and the power density $\left(800 \mathrm{~mW} / \mathrm{cm}^{2}\right)$ of the light was checked with a dental radiometer (Model 100, SDS Kerr) before specimen preparation.

\section{Bond strength test}

Mandibular incisors extracted from 2-3-year-old cattle and stored frozen $\left(-20^{\circ} \mathrm{C}\right)$ for up to 2 weeks were used as a substitute for human teeth. After removing the roots using a slow-speed saw with a diamond-impregnated disk (Isomet, Buehler Ltd., Lake Bluff, IL, USA), the pulps were removed, and the pulp chamber of each tooth was filled with cotton to avoid penetration of the embedding media. The labial surfaces of the bovine incisors were ground on wet 240-grit SiC paper to a flat enamel surface. Each tooth was then mounted in self-curing acrylic resin (Tray Resin II, Shofu Inc., Kyoto, Japan) to expose the flattened area and placed in tap water to reduce the increase in temperature resulting from the exothermic polymerization reaction of the acrylic resin. The final finish was accomplished by grinding on wet 600-grit $\mathrm{SiC}$ paper. After ultrasonic cleaning with distilled water for $1 \mathrm{~min}$ to remove the excess debris, these surfaces were washed and dried with oil-free compressed air.

A piece of double-coated adhesive tape, bearing a 4-mmdiameter hole, was firmly attached to define the area for bonding. The adhesives were only applied without agitation (inactive group) or were lightly agitated with a micro-brush (active group) on the enamel surface for the time recommended by the manufacturers. A Teflon mold, 2.0 $\mathrm{mm}$ high and $4.0 \mathrm{~mm}$ in diameter, was used to form and hold the materials to the tooth surface. The resin composites were condensed into the mold and light-activated for 40 s. The Teflon mold and adhesive tape were removed from the specimens $10 \mathrm{~min}$ after light irradiation. Bonded specimens were stored in water at $37^{\circ} \mathrm{C}$ for $24 \mathrm{~h}$ after placement, then tested in shear mode using a shear knife edge testing apparatus in a universal testing machine (Type 4204, Instron Corp., Canton, MA, USA) at a cross-head speed of $1.0 \mathrm{~mm} / \mathrm{min}$. Shear bond strengths in MPa were calculated from the peak load at failure divided by the specimen surface area.

After testing, the specimens were examined under an optical microscope (SZH-131, Olympus Ltd., Tokyo, Japan) at a magnification of $\times 10$ to determine the location of the bond failure. The test area on the tooth was divided into eight segments, and the percentage that was free of adhesive or restorative material was estimated. The types of failures were determined based on the predominant percentage of substrate-free material as: adhesive failure, cohesive failure in resin composite, cohesive failure in bond agent, and cohesive failure in enamel.

The results were analyzed by calculating the mean shear bond strength $(\mathrm{MPa})$ and standard deviation for each

Table 1 Materials tested

\begin{tabular}{llllll}
\hline $\begin{array}{c}\text { Code Adhesive system } \\
\text { (manufacturer) }\end{array}$ & $\mathrm{pH}$ & Main components & Lot no. & Composite & Lot no. \\
\hline $\mathrm{CT} \quad \begin{array}{l}\text { Clearfil tri-S Bond } \\
\text { (Kuraray Medical) }\end{array}$ & 2.7 & $\begin{array}{l}\text { MDP, bis-GMA, HEMA, initiator, } \\
\text { ethanol, water, stabilizer, filler, } \\
\text { hydrophobic dimethacrylate }\end{array}$ & 011159 & $\begin{array}{l}\text { Clearfil AP-X } \\
\text { (A2) }\end{array}$ & 00080A \\
GB $\begin{array}{l}\text { G-Bond } \\
\text { (GC Corp) }\end{array}$ & 2.8 & $\begin{array}{l}\text { 4-MET, UDMA, acetone, water, } \\
\text { silanated colloidal silica, initiator }\end{array}$ & 0510191 & $\begin{array}{l}\text { Gradia Direct } \\
\text { (A2) }\end{array}$ & 0312121
\end{tabular}

MDP, 10-methacryloxydecyl di-hydrogen phosphate; bis-GMA,

2,2-bis[4-(2-hydrogen-3-methacryloyloxypropoxy)phenyl]propane; HEMA, 2-hydroxyethyl methacrylate; 4-MET, 4-methacryloxyethyl trimellitate; UDMA, urethane dimethacrylate. 
group. The data for each material were tested for homogeneity of variance using Bartelett's test, and then subjected to two-way ANOVA followed by the Tukey HSD test to compare the active and inactive groups, or Duncan's multiple range test to compare the thermal cycling groups at a level of 0.05 . The statistical analysis was carried out with the Sigma Stat software system (Ver. 3.01, SPSS Inc., Chicago, IL, USA).

\section{Scanning electron microscopy}

The treated enamel surfaces were observed by scanning electron microscopy (SEM). For observation of the etched tooth surface, the enamel surfaces were treated with the single-step self-etch adhesive and then rinsed with acetone and water to wipe off the self-etching primer. All the SEM specimens were dehydrated in ascending concentrations of tert-butanol (50\% for $20 \mathrm{~min}, 75 \%$ for $20 \mathrm{~min}, 95 \%$ for $20 \mathrm{~min}$, and $100 \%$ for $2 \mathrm{~h}$ ), and then transferred to a critical-point dryer. The surfaces were coated in a vacuum evaporator (Quick Coater, Type SC-701, Sanyu Denshi Inc., Tokyo, Japan) with a thin film of Au. The specimens were then observed using FE-SEM (ERA-8800FE, Elionix Ltd., Tokyo, Japan).

\section{Results}

The effect of the single-step self-etch adhesive application method on the durability of enamel bond strength is shown in Table 2.

After $24 \mathrm{~h}$ storage in water, the enamel bond strengths of the single-step self-etch adhesive systems of the inactive groups were $13.9 \mathrm{MPa}$ for $\mathrm{CT}$ and $10.8 \mathrm{MPa}$ for GB. For the active groups, the enamel bond strengths were $16.4 \mathrm{MPa}$ for CT and 13.7 MPa for GB. Significant differences were found compared to the same materials in the inactive group for both adhesive systems. Two-way ANOVA revealed that there was no statistically significant interaction between the type of composite restorative system and the adhesive application method employed $(P=0.837)$.

After the enamel bond strength tests, the predominant mode of failure was adhesive failure, consisting of mixed mode for the inactive groups. For the active groups, mixed mode tended to increase, while adhesive failure tended to decrease.

The SEM observations of the enamel surface after single-step self-etch adhesive application are shown in Figs. 1 and 2. For CT, the enamel etching pattern was more pronounced in the active group than in the inactive group,

Table 2 Application protocols of single-step self-etch adhesive systems

CT Dispense one drop of liquid into well. Apply to enamel for $20 \mathrm{~s}$. Subject to a relatively strong stream of air to dry, and light irradiate for $10 \mathrm{~s}$.

GB Dispense one drop of liquid into well. Apply sufficient amount of adhesive for $10 \mathrm{~s}$. Subject to a strong stream of air to dry and light irradiate for $10 \mathrm{~s}$.
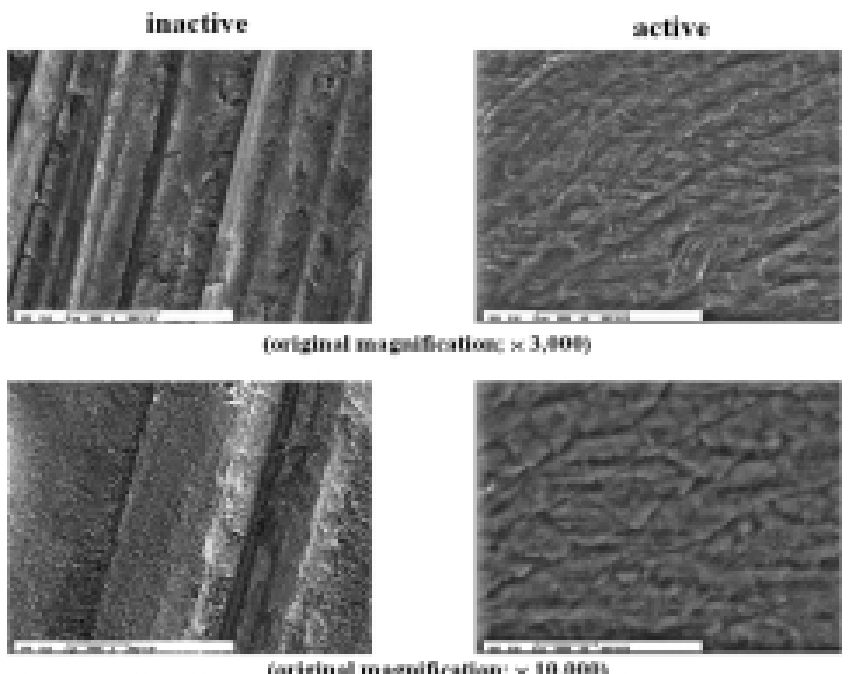

Fig. 1 Enamel surface treated with CT, followed by acetone and water rinsing. With active application of the adhesive, more pronounced demineralization of the enamel surface was observed.
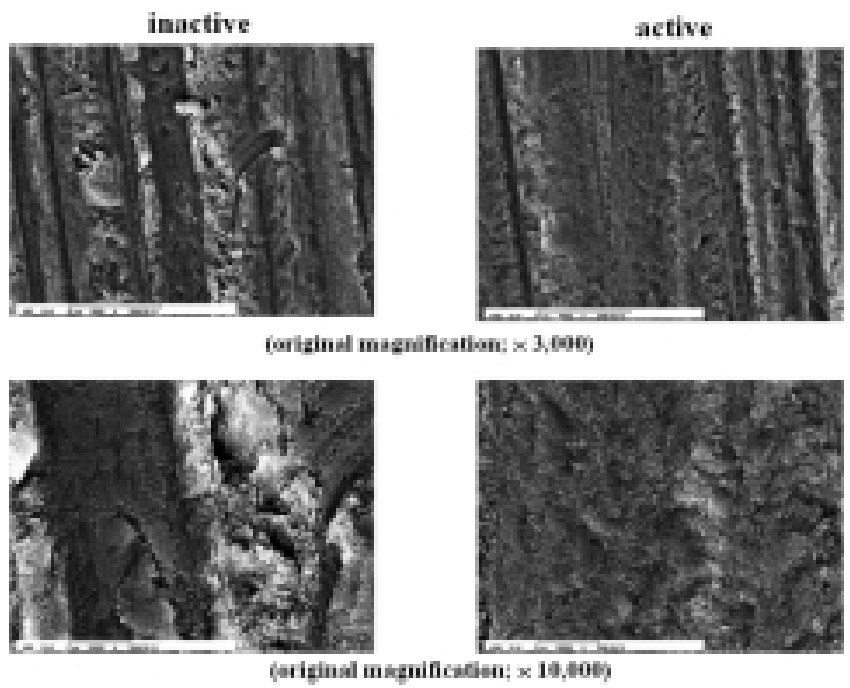

Fig. 2 Enamel surface treated with GB, followed by acetone and water rinsing. Active application of the adhesive produced a demineralized surface similar to that produced by inactive application. 
Table 3 Influence of application methods of self-etching primers on the durability of enamel bond strength

\begin{tabular}{lrrrr}
\hline & \multicolumn{2}{c}{ Bond strength* $^{*}$ Active } & \multicolumn{2}{c}{ Failure mode** } \\
CT & $13.9(2.7)^{\mathrm{a}}$ & $16.4(3.0)^{\mathrm{b}}$ & $7 / 1 / 2$ & Active \\
\hline & & & $4 / 5 / 1$ \\
GB & $10.8(2.0)^{\mathrm{c}}$ & $13.7(1.8)^{\mathrm{a}}$ & $8 / 2 / 0$ & $3 / 0 / 5$ \\
\hline
\end{tabular}

*Mean (standard deviation) in MPa. $\mathrm{n}=10$.

**Failure mode: adhesive failure/mixed failure/cohesive failure in enamel.

Values within same column marked with the same superscript letters showed no significant statistical difference $(P>0.05)$.

which showed some shallow depressions along the enamel surface. Unlike the inactive group, an overall increase in porosity was evident along the entire enamel surface for the active group (Fig. 1). On the other hand, active application of GB produced a demineralized surface similar to that produced by inactive adhesive application (Fig. 2).

\section{Discussion}

Single-step self-etch adhesive systems form a continuous layer by simultaneous demineralization with acidic monomers followed by resin monomer penetration into the enamel surface. The penetration of these acidic monomers into etched enamel creates resin tags. Although there was no relationship between the depth of acid-etching of selfetching primer and bond strength (16), application of single-step self-etch adhesives to unprepared enamel resulted in a shallow etching pattern and insufficient bond strengths (17). It has been reported that a comparatively higher bond strength was obtained for single-step self-etch adhesive systems with prior phosphoric acid application (18).

In this study, inactive application of the adhesive showed a lower bond strength to enamel than active application. This could be due to less demineralization of the enamel by inactive application. The shallower pattern of demineralization associated with inactive treatment could be due to difficulty in penetration of the adhesive into the enamel or some mineral precipitation on the enamel that would modify the depth of demineralization. The role of the active application method may be seen by observing the etching patterns of the enamel. From SEM observations of enamel surfaces primed by active application, the surface debris was removed and the enamel etching pattern was more evident than was the case with inactive application (Fig. 1). The function of active application is to achieve micromechanical interaction with the underlying enamel. The fracture mode varied with adhesive application procedures, and there was an increasing tendency for mixed failure in the active application specimens. When the resin fails to completely infiltrate the deeper portion of the etched enamel, the bonding between enamel and the resin composite might weaken. Active application of single-step self-etch adhesive may help to ensure penetration of the resin monomers into the subsurface enamel substrate.

Based on morphological observations using SEM in this study, active application of GB produced a demineralized surface similar to that produced by inactive application adhesive. The adhesive in single-step selfetch systems is a hydrophilic solution that wets the tooth surface extremely effectively. The etching effect of these systems is related to the acidic monomers or organic acid solutions that may interact with the mineral component of enamel, and enhance monomer penetration. Application of the adhesive allows mineralized tissue to be demineralized and roughened. According to the manufacturers' instructions, the duration of adhesive application is $20 \mathrm{~s}$ for CT and $10 \mathrm{~s}$ for GB. The relatively shorter duration of adhesive application might be related to the morphological change for GB, although enamel bond strength was affected by the adhesive application method.

Bonding to enamel surface relies on resin tag formation in etched enamel to create micromechanical interlocking (19). However, it has been reported that the etching pattern might not be a factor determining enamel bond strength (20). A longer etching time did not result in increased bond strength, although the respective etching patterns observed by SEM were different. Not only the depth of enamel etching, but also the mineral component and the mechanical properties of adhesives may play important roles in determining bond strength. Research has shown that the functional monomers in self-etch adhesives can chemically interact with hydroxyapatite within a clinically manageable time (21), and this chemical interaction has been hy- 
pothesized to have better resistance against degradation by preventing micro- and nanoleakage. According to the adhesion-decalcification concept (22), the less soluble the calcium salt of the acidic molecule, the more intense and stable the molecular adhesion to a hydroxyapatite-based substrate. The adhesive potential of functional monomers with active application might be reflected in the higher bonding performance to enamel

The benefits of enamel bonding include not only a reliable bond of the restoration to the tooth substrate but also reduction of microleakage around the margins. From this study, it can be concluded that the bonding effectiveness of single-step self-etch adhesive systems can be improved by active application of adhesive. Further research must be carried out to evaluate the effect of adhesive application duration on enamel bond strength. Not only the bond strengths but also the duration of integrity of the bonded interface should be evaluated.

\section{Acknowledgments}

This work was supported, in part, , by a Grant-in-Aid for Scientific Research (C) 19592211, 20592237, by Grants-in-Aid for Young Scientists (B) 19791412, 19791415, and 20791397 from the Ministry of Education, Culture, Sports, Science and Technology of Japan, by the Uemura Fund, Sato Fund, and by a grant from the Dental Research Center, Nihon University School of Dentistry.

\section{References}

1. Sano H, Kanemura N, Burrow MF, Inai N, Yamada T, Tagami J (1998) Effect of operator variability on dentin adhesion: students vs. dentists. Dent Mater J $17,51-58$

2. Finger WJ, Balkenhol M (1999) Practitioner variability effects on dentin bonding with an acetonebased one-bottle adhesive. J Adhes Dent 1, 311-314

3. Miyazaki M, Onose H, Moore BK (2000) Effect of operator variability on dentin bond strength of twostep bonding systems. Am J Dent 13, 101-104

4. Van Meerbeek B, De Munck J, Yoshida Y, Inoue S, Vargas M, Vijay P, Van Landuyt K, Lambrechts P, Vanherle G (2003) Buonocore memorial lecture. Adhesion to enamel and dentin: current status and future challenges. Oper Dent 28, 215-235

5. Van Meerbeek B, Van Landuyt K, De Munck J, Hashimoto M, Peumans M, Lambrechts P, Yoshida Y, Inoue S, Suzuki K (2005) Technique-sensitivity of contemporary adhesives. Dent Mater J 24, 1-13

6. Perdigão J, Gomes G, Duarte S Jr, Lopes MM (2005) Enamel bond strengths of pairs of adhesives from the same manufacturer. Oper Dent 30, 492-499
7. Sato M, Miyazaki M (2005) Comparison of depth of dentin etching and resin infiltration with singlestep adhesive systems. J Dent 33, 475-484

8. Yazici AR, Celik C, Ozgünaltay G, Dayangaç B (2007) Bond strength of different adhesive systems to dental hard tissues. Oper Dent 32, 166-172

9. Bates D, Retief DH, Jamison HC, Denys FR (1982) Effects of acid etch parameters on enamel topography and composite resin-enamel bond strength. Pediatr Dent 4, 106-110

10. Retief DH, Busscher HJ, de Boer P, Jongebloed WL, Arends J (1986) A laboratory evaluation of three etching solutions. Dent Mater 2, 202-206

11. Bastos PA, Retief DH, Bradley EL, Denys FR (1988) Effect of etch duration on the shear bond strength of a microfilm composite resin to enamel. Am J Dent $1,151-157$

12. Blosser RL (1990) Time dependence of $2.5 \%$ nitric acid solution as an etchant on human dentin and enamel. Dent Mater 6, 83-87

13. Perdigão J, Lopes L, Lambrechts P, Leitão J, Van Meerbeek B, Vanherle G (1997) Effects of a selfetching primer on enamel shear bond strengths and SEM morphology. Am J Dent 10, 141-146

14. Pashley DH, Tay FR (2001) Aggressiveness of contemporary self-etching adhesives. Part II: etching effects on unground enamel. Dent Mater 17, 430444

15. Hannig M, Bock H, Bott B, Hoth-Hannig W (2002) Inter-crystallite nanoretention of self-etching adhesives at enamel imaged by transmission electron microscopy. Eur J Oral Sci 110, 464-470

16. Tay FR, Pashley DH, King NM, Carvalho RM, Tsai J, Lai SC, Marquezini L Jr (2004) Aggressiveness of self-etch adhesives on unground enamel. Oper Dent 29, 309-316

17. De Munck J, Van Meerbeek B, Satoshi I, Vargas M, Yoshida Y, Armstrong S, Lambrechts P, Vanherle G (2003) Microtensile bond strengths of one- and two-step self-etch adhesives to bur-cut enamel and dentin. Am J Dent 16, 414-420

18. Watanabe T, Tsubota K, Takamizawa T, Kurokawa H, Rikuta A, Ando S, Miyazaki M (2008) Effect of prior acid etching on bonding durability of singlestep adhesives. Oper Dent 33 (in press)

19. Buonocore MG (1955) A simple method of increasing the adhesion of acrylic filling materials to enamel surfaces. J Dent Res 34, 849-853

20. Barkmeire WW, Shaffer SE, Gwinnett AJ (1986) Effects of 15 vs 60 second enamel acid conditioning on adhesion and morphology. Oper Dent 11, 111- 
116

21. Yoshida Y, Van Meerbeek B, Nakayama Y, Snauwaert J, Hellemans L, Lambrechts P, Vanherle G, Wakasa K (2000) Evidence of chemical bonding at biomaterial-hard tissue interfaces. J Dent Res $79,709-714$
22. Yoshida Y, Nagakane K, Fukuda R, Nakayama Y, Okazaki M, Shintani H, Inoue S, Tagawa Y, Suzuki K, De Munck J, Van Meerbeek B (2004) Comparative study on adhesive performance of functional monomers. J Dent Res 83, 454-458 